\title{
Effects of a Safety Letter on Metoclopramide Use in Korea: An Interrupted Time-Series Analysis
}

This article was published in the following Dove Press journal:

Risk Management and Healthcare Policy

\section{Hyungtae Kim (D) \\ Hae Sun Suh}

College of Pharmacy, Pusan National University, Busan, South Korea
Correspondence: Hae Sun Suh

College of Pharmacy, Pusan National

University, Busandaehak-Ro 63 Beon-Gil-2,

Geumjeong-gu, Busan 4624I, South Korea

Tel +82-5I-5I0-2528

Fax +82-5I-5I3-6754

Email haesun.suh@pusan.ac.kr
Background: The Korean Ministry of Food and Drug Safety (MFDS) issued a safety letter regarding metoclopramide use and its adverse drug event of extrapyramidal disorder in October 2013. However, this safety letter had controversial effects on pharmacovigilance and management policies. The objective of this study was to estimate the impact of this government safety letter on the use of metoclopramide.

Patients and Methods: We conducted an interrupted time-series analysis using national claims data from January 2011 to December 2015 to assess the difference in metoclopramide utilization (ie, the total number of prescriptions per month, the average administration period per prescription per month, and the average dose per prescription per month) before and after the publication of the safety letter in October 2013.

Results: The number of prescriptions, the average administration period per prescription, and the average dose per prescription of metoclopramide decreased after the publication of the safety letter. Notably, the decrease in the average administration period per prescription after the safety letter was statistically significant.

Conclusion: Our results indicate that the changes in the number of prescriptions, dose, and the duration of prescription may have occurred as a result of the restrictions and recommendations in the safety letter. Further research is needed to optimize the use of metoclopramide and to identify the risk of adverse drug events since the safety letter was issued.

Keywords: metoclopramide, extrapyramidal disorders, safety alert, ministry of food and drug safety

\section{Introduction}

Metoclopramide is a dopamine antagonist used to prevent nausea and vomiting owing to its antiemetic properties and action as a prokinetic drug. ${ }^{1}$ However, neurologic adverse events caused by metoclopramide, including extrapyramidal disorders, have been reported and are known to be the cause of drug-induced parkinsonism. $^{2-4}$

In February 2009, the Food and Drug Administration (FDA) published a drug safety communication with a black box warning about the adverse drug event of metoclopramide including tardive dyskinesia. ${ }^{5,6}$ The European Medicine Agency (EMA) also recommended changes to the use of metoclopramide, including restrictions on the indication, the maximum administration period, and the maximum daily dose in 2013 . $^{7}$ Based on the EMA recommendations and medical specialists' advice, the Korean Ministry of Food and Drug Safety (MFDS) published a safety letter regarding the use of metoclopramide in October 2013. The safety letter included recommendations with regard to the indications, prescription, and dosage 
of metoclopramide However, the effects of a safety letter from the MFDS during post-marketing surveillance are mixed. Previous studies have shown that a safety letter from the MFDS can change the drug utilization pattern, ${ }^{8}$ whereas other studies have reported that safety letter from the MFDS had a limited impact on treatment use in clinical practice. ${ }^{9}$ A safety letter from the MFDS is an important national policy option in Korea for pharmacovigilance and risk management. ${ }^{9,10}$ A reliable and valid evaluation of the effectiveness of a healthcare policy can be used as evidence to support good decision making in real-world clinical settings. ${ }^{11}$ To effectively manage the serious drug adverse events of metoclopramide such as extrapyramidal disorder and to optimize the impact of the safety letter, it is necessary to evaluate the effectiveness of this policy. Therefore, the objective of this study was to assess the effect of the safety letter on changes in the prescription patterns of metoclopramide in Korea between January 2011 and December 2015.

\section{Materials and Methods}

\section{Data Sources}

We analyzed the national claims data from the Health Insurance Review and Assessment Service (HIRA). HIRA is the government agency that evaluates the medical and pharmacy expenditure of health insurance covering the entire population of approximately 50 million (the Korean National Health Insurance accounts for approximately 97\%, and Medical Aid covers approximately 3\%) in Korea. The claims data from the HIRA contain comprehensive and unidentified information, such as diagnoses, procedures, treatments, surgeries, and prescriptions. ${ }^{12}$ We extracted all claims containing a metoclopramide prescription between 2011 and 2015 from this data to analyze the utilization pattern. This study was exempted from approval by the Institutional Review Board of the Pusan National University Korean Medicine Hospital (PNUIRB/2016_27_HR), owing to the use of anonymized claims data in which participants were not identifiable.

\section{Intervention and Variables}

The MFDS issued the safety letter for metoclopramide in October 2013; this safety letter included the following: (1) With regard to indications; the recommendation that metoclopramide should not be prescribed as a single agent for gastrointestinal disorders and as an adjunct in surgical and radiological procedures and that metoclopramide should only be used as a second-line option for the prevention of postoperative nausea and vomiting and delayed chemotherapy-induced nausea and vomiting in children; (2) with regard to prescription; the recommendation that metoclopramide should only be prescribed for short-term use (up to 5 days); (3) with regard to dosage; the recommendation that the maximum dose of metoclopramide that should be prescribed in 24 hours should be $0.5 \mathrm{mg} / \mathrm{kg}$ for adults and children; and (4) with regard to age; the recommendation that metoclopramide is contra-indicated in children under 1 year of age. ${ }^{13}$ Through these recommendations limiting the indication, prescription period, and dosage, the MFDS tried to minimize the risk of adverse drug events caused by metoclopramide. We hypothesized that the utilization pattern of metoclopramide, including the number of prescriptions, prescription period, and dosage, would be decreased after the publication of the safety letter compared with that before publication. To evaluate this, we estimated three types of outcomes to analyze the effect of the safety letter on the utilization patterns of metoclopramide. First, we estimated the number of prescriptions per month to assess the impact of the restriction of the indications in the safety letter on the utilization pattern. Next, we estimated the average administration period per prescription per month to evaluate the association between the recommendation on the maximum administration period in the safety letter and the change in the prescription patterns of metoclopramide. Finally, we measured the average dose per prescription per month to analyze the effect of the restriction of the daily maximum dose on utilization change.

\section{Data Analysis}

To assess the change in the utilization pattern, we conducted an interrupted time-series analysis (ITSA) using HIRA claims data that included metoclopramide usage between January 2011 and December 2015. ITSA is one of the most useful and simple quasi-experimental designs for the identification of the impact of healthcare policies or interventions when a randomized controlled trial is not possible or clinical trial data are not available. Many researchers have used ITSA methodologies to evaluate the effectiveness of healthcare policies. ${ }^{8,14-19}$ In recent years, several studies have suggested a scientific process and recommendations for ITSA including methodology and reporting. We performed an ITSA comparing the utilization pattern of metoclopramide before and after the 
publication of the safety letter with reference to these recommendations. ${ }^{11,20-24}$ In the ITSA, the regression line is segmented before and after the occurrence of the intervention or event to be analyzed. Each segmented regression line is represented by two parameters, level (or intercept) and slope (or trend). The impact of the event on the outcomes can be described in terms of a change in the level or slope. The segmented regression model for ITSA was as follows:

$$
\begin{aligned}
Y_{t}= & \beta_{0}+\beta_{1} \times T I M E 1_{t}+\beta_{2} \times P O L I C Y+\beta_{3} \times T I M E 2_{t} \\
& +\varepsilon_{t}
\end{aligned}
$$

where $Y_{t}$ was the outcome variable (ie, the number of prescriptions, the average administration period per prescription, and the average dose per prescription) over time t; TIME1 was the continuous time in months from 0 (for January 2011) to 60 (for December 2015); POLICY was a binary variable indicating the publication of the safety letter as the point intervention, where 1 indicated that it had been published and 0 indicated that it has not; TIME2 is the continuous time in months from 0 (for October 2013) to 26 (for December 2015), with a value of 0 before the publication of the safety letter. The error term $\varepsilon_{\mathrm{t}}$ refers to a random variable that cannot be explained by the model. In this model, the coefficient $\beta_{0}$ indicated the baseline level of the outcomes per month when TIME1 was zero (for January 2011); $\beta_{1}$ estimated the baseline trend before the publication of the safety letter; $\beta_{2}$ estimated the outcome change immediately after the publication of the safety letter; and $\beta_{3}$ represented the change in the trend after the safety letter was released, compared with $\beta_{1}$. Thus, $\beta_{1}+\beta_{3}$ shows the outcome (change in the trend) after the safety letter was issued.

For this segmented linear regression, it is important to control for autocorrelation and seasonality. Autocorrelation represents a serial correlation between adjacent outcome data. ${ }^{21,22}$ For example, the drug utilization pattern in time $e_{k}$ may be correlated with time $e_{k+1}$, through a first-order autocorrelation. If the time unit of ITSA is months and the order of autocorrelation is 12 or 24 months, it is an example of seasonality. ${ }^{22}$ Autocorrelation may lead to biased results, including an underestimated standard error and overestimated significance. $^{22}$ To detect and correct autocorrelation among the observations, we performed an ITSA with the Durbin-Watson test. ${ }^{21}$ Then, to correct for autocorrelation, we used the Yule-Walker method with the BACKSTEP option. This method can automatically test for correlations and sequentially removes insignificant autoregressive parameters until only significant autoregressive parameters remain at the 0.05 level. $^{21,25-27}$

The other issue to consider in ITSA is immediacy. Immediacy is described as the amount of delayed (or lagged) time until the effect of the intervention occurs. ${ }^{20-22,24,28}$ For example, if a policy is implemented, the policy may take a certain period of time to have an effect on the clinical event. ${ }^{20-22}$ Therefore, researchers should consider the appropriate lag time for the proper effect to appear in the segmented regression model. In this study, we hypothesized that there would be a time lag of approximately 4 months for the complete impact of the metoclopramide safety letter to be evident. ${ }^{20-22,24}$ To take this issue into consideration, we excluded the lag time period (between October 2013 and February 2014) from the analysis by referring to previous studies. ${ }^{22}$ We performed all analyses using SAS version 9.4 (Copyright SAS Institute Inc., Cary, NC, USA).

\section{Results}

We analyzed 40,730,545 prescriptions for metoclopramide between January 2011 and December 2015 from the HIRA claims data $(29,857,752$ cases before safety letter issuance and 10,872,793 cases after safety letter issuance). The results of the ITSA, including the trends in the utilization patterns per month during the study period, are shown in Figure 1. The number of prescriptions per month $(718,182-1,183,194$ before the publication of the safety letter and 328,215-566,043 after the publication of the safety letter) followed no significant trend (TIME1: 3435 , p-value $=0.09$ ), and there was no significant alteration in the trend after the publication of the safety letter (TIME2: -4705 , p-value $=0.26$ ). However, the number of prescriptions per month decreased immediately after the safety letter was released (POLICY: $-531,543$, p-value $<0.01$ ). The trend in the average administration period per prescription per month (4.28-4.94 days before the publication of the safety letter and 2.55-3.78 days after the publication of the safety letter) did not show a significant change before the safety letter (TIME1: 0.01, p-value = 0.09). However, after the release of the safety letter, the estimate and trend were significantly decreased compared with that before the publication of the safety letter (POLICY: -1.32 , p-value $<0.01$; TIME2: -0.05 , p-value $<0.01)$. The average dose per prescription per month (18.27-19.21 mg before the publication of the safety letter and $15.39-16.93 \mathrm{mg}$ after the publication of safety letter) followed a decreasing trend before the safety letter (TIME1: -0.02 , p-value $<0.01$ ). The average 

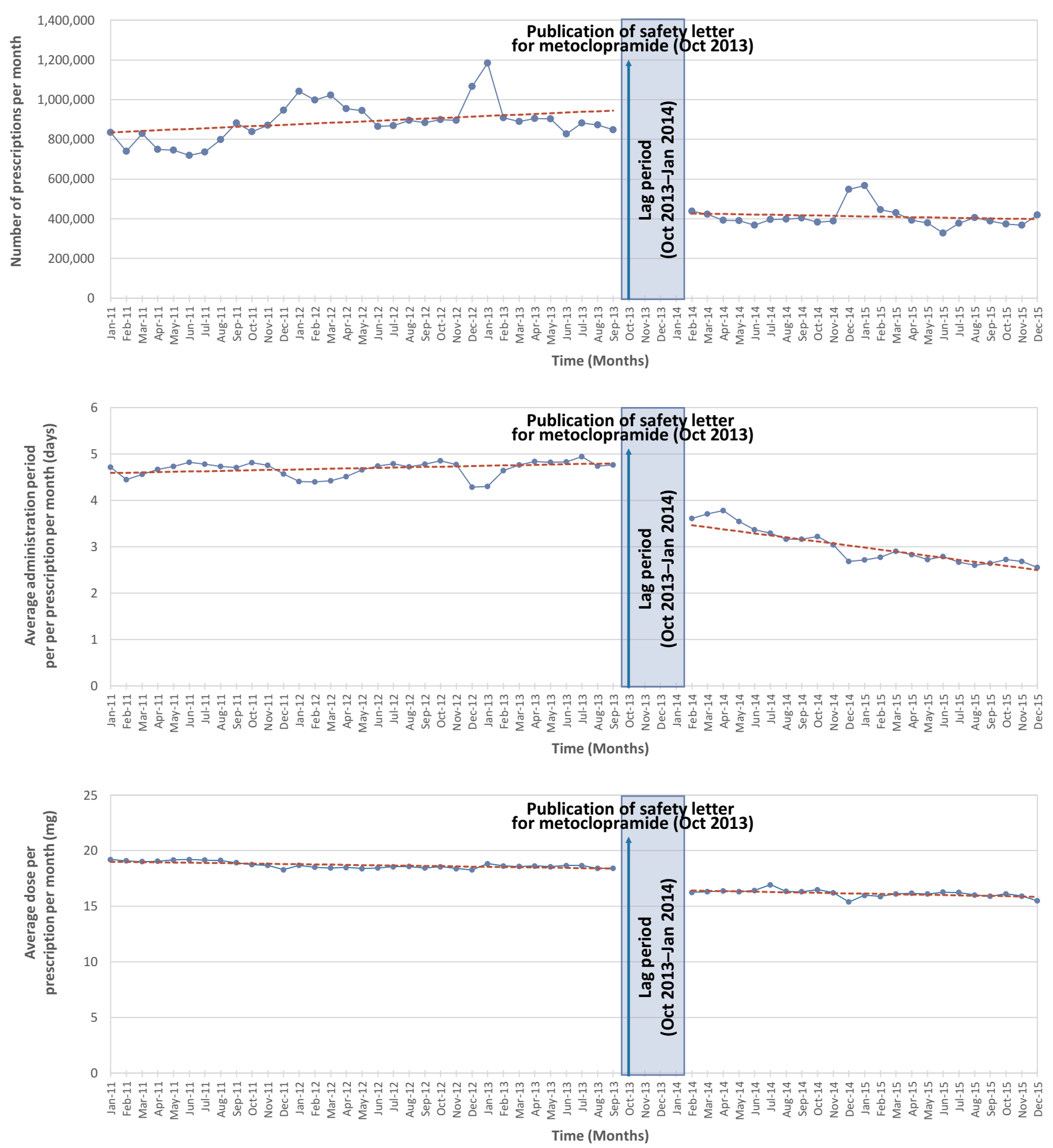

Figure I Results of the interrupted time-series analysis with segmented regression method.

dose per prescription per month decreased immediately after the publication of the safety letter (POLICY: -1.88 , $\mathrm{p}$-value $<0.01$ ) and there was no significant change in the trend compared with that before the safety letter was released (TIME2: $-0.01, \mathrm{p}$-value $=0.63)($ Table 1$)$. The absolute values of the outcomes per month are presented in the supplementary data.

\section{Discussion}

This study showed that the recommendations in the safety letter published by the MFDS, which restricted the indications, maximum dose to be administered, and maximum daily dose of metoclopramide, may be associated with a change in utilization patterns in Korea. The number of prescriptions per month, the average administration period 
Table I Parameters from the Interrupted Time-Series Analysis of Utilization Patterns

\begin{tabular}{|c|c|c|c|c|c|c|c|c|}
\hline \multirow[t]{2}{*}{ Utilization Pattern } & \multicolumn{2}{|l|}{ Intercept } & \multicolumn{2}{|l|}{ TIMEI } & \multicolumn{2}{|l|}{ POLICY } & \multicolumn{2}{|l|}{ TIME2 } \\
\hline & $\begin{array}{l}\beta_{0} \\
\text { Estimates } \\
\text { (SE) }\end{array}$ & p-value & $\begin{array}{l}\beta_{\text {I }} \\
\text { Estimates } \\
\text { (SE) }\end{array}$ & p-value & $\begin{array}{l}\boldsymbol{\beta}_{2} \\
\text { Estimates } \\
\text { (SE) }\end{array}$ & p-value & $\begin{array}{l}\beta_{3} \\
\text { Estimates } \\
\text { (SE) }\end{array}$ & p-value \\
\hline Number of prescriptions per month & $\begin{array}{l}831,799 \\
(39,296)\end{array}$ & $<0.01$ & $\begin{array}{l}3435 \\
(1988)\end{array}$ & 0.09 & $\begin{array}{l}-531,543 \\
(60,898)\end{array}$ & $<0.01$ & $\begin{array}{l}-4705 \\
(410 I)\end{array}$ & 0.26 \\
\hline $\begin{array}{l}\text { Average administration period per } \\
\text { prescription per month (days) }\end{array}$ & $\begin{array}{l}4.58 \\
(0.08)\end{array}$ & $<0.01$ & $\begin{array}{l}0.01 \\
(0.003)\end{array}$ & 0.09 & $\begin{array}{l}-1.32 \\
(0.1 I)\end{array}$ & $<0.01$ & $\begin{array}{l}-0.05 \\
(0.01)\end{array}$ & $<0.01$ \\
\hline $\begin{array}{l}\text { Average dose per prescription per month } \\
(\mathrm{mg})\end{array}$ & $\begin{array}{l}19.03 \\
(0.13)\end{array}$ & $<0.01$ & $\begin{array}{l}-0.02 \\
(0.007)\end{array}$ & $<0.01$ & $\begin{array}{l}-1.88 \\
(0.19)\end{array}$ & $<0.01$ & $\begin{array}{l}-0.01 \\
(0.01)\end{array}$ & 0.63 \\
\hline
\end{tabular}

Notes: Intercept is a value of utilization pattern in January 20II. TIMEI is a continuous variable that takes the value of "I" for January $20 \mathrm{II}$ and increases by one per month. TIME2 starts at 0 , takes the value of "I" for October 2013 , and increases by one per month. POLICY is a dummy variable representing the publication of the safety letter in October 2013.

Abbreviation: SE, standard deviation.

per prescription per month, and the average dose per prescription per month decreased significantly after the publication of the safety letter. These decreases may have been attributable to the safety letter. Among the changes in the prescribing patterns, only the average administration period per prescription per month after the release of the safety letter decreased significantly compared with that before the publication of the safety letter. This may be related to the characteristics of extrapyramidal disorders as a side effect of metoclopramide. The occurrence of extrapyramidal disorders is closely related to the period of metoclopramide use. ${ }^{29}$ Owing to the issuance of the safety letter by the MFDS, the prescription period of metoclopramide may have been gradually shortened as much as possible to minimize the occurrence of these adverse drug events.

The issuance of a safety letter by the MFDS is an important post-marketing drug safety management system used in Korea. If the discontinuation or restriction of drug use is required owing to the potential risk of severe adverse drug events, the MFDS will rapidly release a safety letter and perform various follow-up actions, such as the revocation or amendment of pharmaceutical approval. ${ }^{30}$ The safety letter summarizes evidence from domestic and foreign drug safety and contains cautionary information on prescribing, dosing, dispensing, and administration. The Korean government and MFDS established a drug utilization review (DUR) system in 2008 to monitor adverse drug event in real time based on postmarketing pharmacovigilance systems such as a safety letter. ${ }^{31}$ However, the DUR system provided very limited information, and the impact of the safety letter by the MFDS on clinical practice is uncertain and controversial. ${ }^{9}$ A previous study, which analyzed the safety letters issued by the MFDS between 2001 and 2011, reported that the safety letters did not affect actual clinical practice owing to the inefficient system for risk communication. ${ }^{9}$ Therefore, it is necessary to provide evidence to support the improvement of public health through safe medication use, by evaluating the impact of the safety letter. The results of our study showed that the MFDS safety letter for metoclopramide was associated with an immediate reduction in utilization patterns. The safety letter for metoclopramide issued in October 2013 contained an amendment for metoclopramide approval, as well as recommendations for changes to the use of metoclopramide, with restrictions on the indication, maximum administration period, and maximum daily dose. ${ }^{13}$ A recent study evaluating a safety letter for pioglitazone also showed similar results. ${ }^{32}$ This study showed that the release of a safety letter including a warning regarding the risk of bladder cancer led to a moderate decrease in pioglitazone users. According to another study that assessed the effect of the FDA's post-marketing drug safety surveillance on the use of metoclopramide, a black box warning about the adverse events of metoclopramide has decreased drug usage. ${ }^{6}$ In addition, several studies on the drug safety management system have reported the significant impact on drug utilization patterns. ${ }^{14,33-35}$ Based on these results, the safety letter issued by the MFDS can be regarded as a factor that influences a change in prescribing patterns. In particular, if there are strong actions, such as the revocation or amendment of pharmaceutical approval, the relationship between safety letters and changes in prescribing patterns may become apparent. 
To the best of our knowledge, this is the first study to assess the effect of the publication of a safety letter by the MFDS on changes in the prescribing patterns of metoclopramide in Korea. In addition, we conducted an ITSA using nationally representative claims data that covers the entire population. Previous studies analyzing the effect of policy on metoclopramide in the US and Europe have used limited data sources. ${ }^{6,19}$ These studies showed the change in the utilization pattern of metoclopramide by examining the electronic medical records of an university hospital over 24 or 30 months, comparing that before and after the policy implementation. ${ }^{6,19}$ Compared with these studies, our study analyzed national insurance claims data covering the whole population over 60 months, thereby ensuring the representativeness of our research results. We did not investigate the impact of the metoclopramide safety letter on the use of alternative drugs such as domperidone. Further investigations may be needed to identify the effect of the safety letter of metoclopramide on the drugs that have replaced metoclopramide.

Despite these strengths, we should interpret the results with caution owing to the limitations of the interrupted time-series study design. If there were other factors associated with the use of metoclopramide in addition to the events or policies that we were interested in, these may have affected the results. ${ }^{22}$ However, to the best of our knowledge, no other policies or events could have directly affected metoclopramide use other than the safety letter issued in October 2013.

\section{Conclusion}

This study suggests that the safety letter containing recommendations on medication usage and the amendment of pharmaceutical approval issued by the MFDS was associated with changes in the prescription patterns of metoclopramide. The results of our study may be used as evidence for the evaluation of the effectiveness of the safety letter as a post-marketing surveillance policy. Further studies to explore the characteristics of safety letters and optimize their impact may contribute to the development of safety letters as a more effective drug safety management system.

\section{Data Sharing Statement}

The data that support the findings of this study are available from Health Insurance Review and Assessment but restrictions apply to the availability of these data, which were used under license for the current study, and so are not publicly available. Data are however available from the authors upon reasonable request and with permission of Health Insurance Review and Assessment.

\section{Ethical Approval}

This study was certified as exempt from the ethical review by the Institutional Review Board of the Pusan National University (IRB number: 201627HR).

\section{Funding}

This research was supported by Basic Science Research Program through the National Research Foundation of Korea (NRF) funded by the Ministry of Education, Science and Technology (NRF-2016R1C1B1009198).

\section{Disclosure}

All authors report no conflicts of interest in this work.

\section{References}

1. DiPiro JT, Talbert RL, Yee GC, et al. Pharmacotherapy: A Pathophysiologic Approach. 6th ed. New York: McGraw-Hill Medical; 2014.

2. Shin H-W, Chung SJ. Drug-induced parkinsonism. J Clin Neurol. 2012;8(1):15-21. doi:10.3988/jen.2012.8.1.15

3. Blanchet PJ, Kivenko V. Drug-induced parkinsonism: diagnosis and management. Res Rev Parkinsonism. 2016;6:83-91.

4. Kim S, Cheon S-M, Suh HS. Association between drug exposure and occurrence of parkinsonism in Korea: a population-based case-control study. Ann Pharmacother. 2019;53(11):1102-1110. doi:10.1177/1060028019859543

5. Food and Drug Administration. FDA requires boxed warning and risk mitigation strategy for metoclopramide-containing drugs. Available from: https://wayback.archive-it.org/7993/20170112033201/http:// www.fda.gov/NewsEvents/Newsroom/PressAnnouncements/2009/ ucm149533.htm. Accessed July 20, 2020.

6. Ehrenpreis ED, Deepak P, Sifuentes H, et al. The metoclopramide black box warning for tardive dyskinesia: effect on clinical practice, adverse event reporting, and prescription drug lawsuits. $\mathrm{Am}$ J Gastroenterol. 2013;108(6):866-872. doi:10.1038/ajg.2012.300

7. European Medicines Agency. European medicines agency recommends changes to the use of metoclopramide; Published 2013. Available from: https://www.ema.europa.eu/en/news/europeanmedicines-agency-recommends-changes-use-metoclopramide. Accessed July 20, 2020.

8. Rhew K, Han N, Oh JM. Impact of safety warning on domperidone prescribing for geriatric patients in South Korea: analysis of national insurance claim data. Int J Env Res Pub He. 2019;16(16):2985. doi:10.3390/ijerph16162985

9. Kim M-S, Shin J-Y, Kim J-Y, et al. Analysis of safety letters and alerts in Korea food \& drug administration, 20012011. Korean Soc Pharmacoepidem Risk Manag. 2013;6(1):37-42.

10. Chung S, Ahn S-H, Kim S, et al. Development of systematic target drug prioritization process in Korea. International Conference on Pharmacoepidemiology \& Therapeutic Risk Management; August 26, 2013; Montréal, QC.

11. Ramsay CR, Matowe L, Grilli R, Grimshaw JM, Thomas RE. Interrupted time series designs in health technology assessment: lessons from two systematic reviews of behavior change strategies. Int J Technol Assess Health Care. 2003;19(4):613-623. doi:10.1017/ S0266462303000576 
12. Kim J-A, Yoon S, Kim L-Y, Kim D-S. Towards actualizing the value potential of korea health insurance review and assessment (HIRA) data as a resource for health research: strengths, limitations, applications, and strategies for optimal use of HIRA data. J Korean Med Sci. 2017;32(5):718-728. doi:10.3346/jkms.2017.32.5.718

13. Ministry of Foods and Drugs Safety. Issuance of a safety letter for medications containing metoclopramide. Available from: https:// nedrug.mfds.go.kr/pbp/CCBAC01/getItem?totalPages $=26 \& 1$ imit $=$ $10 \&$ search $\mathrm{Yn}=$ true $\&$ page $=1 \&$ title $=\% \mathrm{~EB} \% \mathrm{~A} \% \% 94 \% \mathrm{ED} \% 86 \%$ A0\&safeLetterNo=117. Accessed July 20, 2020.

14. Kesselheim AS, Donneyong M, Dal Pan GJ, et al. Changes in prescribing and healthcare resource utilization after FDA drug safety communications involving zolpidem containing medications. Pharmacoepidemiol Drug Saf. 2017;26(6):712-721. doi:10.1002/pds.4215

15. Kesselheim AS, Campbell EG, Schneeweiss S, et al. Methodological approaches to evaluate the impact of FDA drug safety communications. Drug Saf. 2015;38(6):565-575. doi:10.1007/ s40264-015-0291-y

16. Park J, Han E, Lee SO, Kim D-S, Wang Y-T. Antibiotic use in South Korea from 2007 to 2014: A health insurance database-generated time series analysis. PLoS One. 2017;12(5):e0177435. doi:10.1371/ journal.pone.0177435

17. Park C-M, Lee K-S, Han E, Kim D-S. Effects of delisting nonprescription combination drugs on health insurance expenditures for pharmaceuticals in Korea. Health Policy. 2016;120(6):590-595. doi:10.1016/j.healthpol.2016.05.003

18. Han E, Chae S-M, Kim N-S, Park S. Effects of pharmaceutical cost containment policies on doctors' prescribing behavior: focus on antibiotics. Health Policy. 2015;119(9):1245-1254. doi:10.1016/j. healthpol.2015.05.005

19. Colón A, Gómez Gómez D, Gómez Esteban A, et al. DI-086 Influence of the recommendations of the european medicines agency regarding the modification of the prescription pattern of metoclopramide. Eur J Hosp Pharm. 2015;22(Suppl 1):A108. doi:10.1136/ejhpharm-2015-000639.260

20. Jandoc R, Burden AM, Mamdani M, Lévesque LE, Cadarette SM. Interrupted time series analysis in drug utilization research is increasing: systematic review and recommendations. $J$ Clin Epidemiol. 2015;68(8):950-956. doi:10.1016/j.jclinepi.2014.12.018

21. Penfold RB, Zhang F. Use of interrupted time series analysis in evaluating health care quality improvements. Acad Pediatr. 2013;13 (6):S38S44. doi:10.1016/j.acap.2013.08.002

22. Wagner AK, Soumerai SB, Zhang F, Ross-Degnan D. Segmented regression analysis of interrupted time series studies in medication use research. J Clin Pharm Ther. 2002;27(4):299-309. doi:10.1046/ j.1365-2710.2002.00430.x

23. Cochrane Effective Practice and Organisation of Care (EPOC). Interrupted time series (ITS) analyses: EPOC resources for review authors; Published 2017. Available from: https:/epoc.cochrane.org/ sites/epoc.cochrane.org/files/public/uploads/Resources-forauthors2017/interrupted_time_series_analyses.docx.
24. Bernal JL, Cummins S, Gasparrini A. Interrupted time series regression for the evaluation of public health interventions: a tutorial. Int J Epidemiol. 2017;46(1):348-355. doi:10.1093/ije/dyw098

25. Slavova S, Costich JF, Luu H, et al. Interrupted time series design to evaluate the effect of the ICD-9-CM to ICD-10-CM coding transition on injury hospitalization trends. Inj Epidemiol. 2018;5(1):1-12. doi: 10.1186/s40621-018-0165-8

26. Ma Z-Q, Kuller LH, Fisher MA, Ostroff SM. Peer reviewed: use of interrupted time-series method to evaluate the impact of cigarette excise tax increases in pennsylvania, 2000-2009. Prev Chronic Dis. 2013;10(120268):1-10. doi:10.5888/pcd10.120268

27. Caswell $\mathrm{J}$ Interrupted time series analysis for single series and comparative designs: a guide for beginners with sas macro; 2017. Available from: https://www.academia.edu/35275583/Interrupted_Time_Series Analysis_for_Single_Series_and_Comparative_Designs_A_Guide_ for_Beginners_with_SAS_Macro. Accessed July 20, 2020.

28. Bernal JL. The Use of Interrupted Time Series for the Evaluation of Public Health Interventions [Dissertation]. London: London School of Hygiene \& Tropical Medicine; 2018.

29. Miller LG, Jankovic J. Metoclopramide-induced movement disorders: clinical findings with a review of the literature. Arch Intern Med. 1989;149(11):2486-2492. doi:10.1001/archinte.1989.00390110070015

30. Choi D, Choi M, Ko A. Current status of pharmaceutical safety management in Korea. J Korean Med Assoc. 2012;55(9):827-834. doi:10.5124/jkma.2012.55.9.827

31. Shin JY, Jung SY, Ahn SH, et al. New initiatives for pharmacovigilance in South Korea: introducing the Korea Institute of Drug Safety and risk management (KIDS). Pharmacoepidemiol Drug Saf. 2014;23(11):1115-1122. doi:10.1002/pds.3715

32. Jeong HE. Prescribing Trend of Pioglitazone After Safety Warning Release in South Korea [Dissertation]. Seoul: Graduate school of Seoul National University; 2018.

33. Bjerre LM, Parlow S, De Launay D, et al. Comparative, cross-sectional study of the format, content and timing of medication safety letters issued in Canada, the USA and the UK. BMJ Open. 2018;8(10):e020150. doi:10.1136/bmjopen-2017-020150

34. Thomas SK, Hodson J, McIlroy G, Dhami A, Coleman JJ. The impact of direct healthcare professional communication on prescribing practice in the UK hospital setting: an interrupted time series analysis. Drug Saf. 2013;36(7):557-564. doi:10.1007/s40264-013-0057-3

35. Stewart KA, Natzke BM, Williams T, et al. Temporal trends in antidiabetes drug use in tricare following safety warnings in 2007 about rosiglitazone. Pharmacoepidemiol Drug Saf. 2009;18 (11):1048-1052. doi:10.1002/pds.1819
Risk Management and Healthcare Policy

\section{Publish your work in this journal}

Risk Management and Healthcare Policy is an international, peerreviewed, open access journal focusing on all aspects of public health, policy, and preventative measures to promote good health and improve morbidity and mortality in the population. The journal welcomes submitted papers covering original research, basic science, clinical \& epidemiological studies, reviews and evaluations, guidelines, expert opinion and commentary, case reports and extended reports. The manuscript management system is completely online and includes a very quick and fair peer-review system, which is all easy to use. Visit http://www.dovepress.com/testimonials.php to read real quotes from published authors. 